\title{
Impact of the COVID-19 pandemic on the generation of plastic waste in the catering business (Case study of Tan Thinh ward, Thai Nguyen city, Vietnam)
}

\author{
Tran Thi Ngoc Ha \\ Thai Nguyen University of Science, Vietnam \\ DOI: 10.29322/IJSRP.12.01.2022.p12153 \\ http://dx.doi.org/10.29322/IJSRP.12.01.2022.p12153
}

\begin{abstract}
The article focuses on assessing the effects of COVID-19 pandemic on catering business and the generation of plastic waste from this activity in Tan Thinh ward, Thai Nguyen city, Vietnam. The study conducted a survey of all 129 restaurants in 3 groups with the largest number of stores in Tan Thinh ward. The results show that the COVID-19 pandemic had a great impact on the catering business of Tan Thinh ward. The generation of plastic waste depends on the type of food business. Small restaurants, street stand stores selling items such as sticky rice, bread, stuffed pancake, noodles soup, kebab rice noodle... using plastic bags and single-use plastics increased because of the increase in the number of take-out customers. Great restaurants generate fewer single-use plastic bags and items because they tend to close during an outbreak.
\end{abstract}

Index Terms- Plastic, waste, Tan Thinh, COVID-19, Vietnam

\section{INTRODUCTION}

$\mathrm{T}$ he COVID-19 pandemic has seriously affected the life, economy and society of many different countries around the world, including Vietnam. According to Vietnam's Ministry of Health Portal on the COVID-19 pandemic on December 29, 2021, the total number of intected people in the world reached 281.953.863 people and the number of deaths was 5.425.246 people (accounting for $1,92 \%$ of infected people) [1]. In Vietnam, the death rate was lower than the death world rate (accounting for 1,88\%) (with 1.680 .985 infected people and 31.632 deaths) [1]. During the fourth outbreak of the COVID-19 pandemic (starting from April 2021 to present), many production facilities, industrial parks, restaurants and bars had to close. The economy was badly damaged. Gross domestic product (GDP) in the third quarter of 2021 was estimated to decrease by $6,17 \%$ over the same period last year [2]. Social evils increased rapidly. In the third quarter of 2021, Vietnam had 4,7 million people lost their jobs, 14,7 million people had to temporarily stop working, 12 million people had their working hours reduced [2]. People's lives faced many difficulties and poverty.

Many measures were taken by governments to control and limit the spread of the disease, such as: social distancing, limit contact, close public places, use masks, only sell food take away ... However, the priorities of pandemic prevention and public health were put first, the impact of COVID-19 on the environment was not paid attention [3]. According to Ana L.Patricio Silvaa et al, although greenhouse gas emissions and noise in big cities were reduced by COVID-19 pandemic, the amount of plastic waste (especially singleuse plastics) increased [3]. The demand for plastic bag and single-use plastics increased due to people's fear of pandemic [4]. Even in some countries, regulations on restricting the use of single-use plastic products were forced to pause to ensure social safety. The increase in online shopping and takeout also increased the amount of plastic bags and single-use plastics in the storage and transportation of goods. Therefore, the emergence and outbreak of the COVID-19 pandemic will probably bring all human efforts in reducing plastic emissions worldwide back to the starting point.

Plastic bags and single-use plastics used in product packaging, catering business were not only popular in Vietnam but also around the world because of many advantages (convenience, cheapness, lightness ...) [5]. According to a United Nations report, more than 8.3 billion tons of plastic have been produced since the early 1950s and about $60 \%$ of them ended up in landfills or the natural environment [6]. From the 1970s onwards, plastic materials gradually replaced other materials (such as glass, wood, paper, etc.) to store food in restaurants, bars, and cafes. According to the US Environmental Protection Agency (EPA), it is estimated that about 14.5 million tons of plastic containers and food packaging were created in 2018 [7].

Vietnam was considered as one of the 20 countries that use and dispose of the most plastic waste in the world [8]. On average, Vietnam generates 1.8 million tons of plastic waste per year ( $18.5 \mathrm{~kg} /$ person/year) [8]. About $50 \%$ of plastic products was produced for single-use and then discarded [9]. Currently, there was many studies on the impact of the COVID-19 pandemic on the generation of plastic waste in the world. However, these studies in Vietnam was still very limited .

Tan Thinh ward is located in the western area of Thai Nguyen city. There are 5 universities, 3 preschools, 1 primary school, 1 junior high school, about 100 agencies, organizations, businesses, 7 military barracks, and 2779 households in the area [10]. Therefore, the catering business in the area was quite developed. 
The study focuses on assessing the impact of the COVID-19 pandemic on the catering business and the generation of plastic waste from these activities in Tan Thinh ward, Thai Nguyen city, Vietnam. These were facilities that serve the local plastic waste management.

\section{METHODOLOGY}

Collect, analyze and process data: The collected data includes natural conditions, socio-economic, catering business, policies on plastic waste in the study area... The collected documents was synthesized, analyzed and processed to be used for the article.

Fieldwork, survey: The article focuses on research within Group 1, Group 2 and Group 6 of Tan Thinh ward because these were groups with the most restaurants in the area. Surveyed all 129 catering stores in Tan Thinh ward to assess the impact of the Covid19 pandemic on business activities and the generation of plastic waste.

The study classified catering stores in Tan Thinh ward into small types:

Type I: Street stand stores (selling sticky rice, steamed wheat flour cake, bread, juice...).

Type II: Small restaurants ( selling stuffed pancake, noodles soup, porridge, sticky rice, kebab rice noodle,...).

Type III: Great restaurants (all day sale) (hot pot restaurant, barbecue restaurant...).

Type IV: Drink, fastfood stores (selling coffee, lemon tea, yogurt, milk tea, ice cream, pizza, hot dog...).

Type V: Sidewalk refreshment stores (selling beer, iced tea, sugarcane juice...).

Table 1:- Number of surveyed stores in Tan Thinh ward

\begin{tabular}{lcccc}
\hline Type of stores & Group 1 & Group 2 & Group 6 & Total \\
\hline Street stand stores & 4 & 3 & 1 & 8 \\
\hline Small restaurants & 21 & 20 & 15 & 56 \\
\hline Great restaurants & 2 & 3 & 8 & 13 \\
\hline Drink, fastfood stores & 16 & 11 & 10 & 37 \\
\hline Sidewalk refreshment stores & 6 & 5 & 4 & 15 \\
\hline Total & $\mathbf{4 9}$ & $\mathbf{4 2}$ & $\mathbf{3 8}$ & $\mathbf{1 2 9}$ \\
\hline
\end{tabular}

\section{RESULT AND DISCUSSION}

\subsection{Impact of COVID-19 pandemic on catering business in Tan Thinh ward}

Since 2021, the COVID-19 pandemic has been complicated, so the catering business in Tan Thinh ward faced many difficulties. Some stores had to close or reduce operating hours because the number of customers coming to the store decreased. Especially, stores that rent space for business faced more difficulties. The extent of the impact of the COVID-19 pandemic on the business situation of stores was shown in Table 2 and Figure 1.

Table 2:- Impact of COVID-19 pandemic on the catering stores in Tan Thinh ward

\begin{tabular}{lccccc}
\hline \multirow{2}{*}{ Group } & \multirow{2}{*}{ The number of stores } & \multicolumn{4}{c}{ Percentage of stores affected to varying degrees } \\
\cline { 2 - 6 } & & Unaffected & Less affected & Affected & Greatly affected \\
\hline Group 1 & 49 & 0 & 8,1 & 18,3 & 73,6 \\
\hline Group 2 & 42 & 0 & 11,93 & 23,83 & 64,24 \\
\hline Group 6 & 38 & 0 & 7,89 & 15,78 & 76,33 \\
\hline Tổng & $\mathbf{1 2 9}$ & $\mathbf{0}$ & $\mathbf{9 , 3}$ & $\mathbf{1 9 , 4}$ & $\mathbf{7 1 , 3}$ \\
\hline & & & & $*$ * Source: Surveyed results in September 2021
\end{tabular}




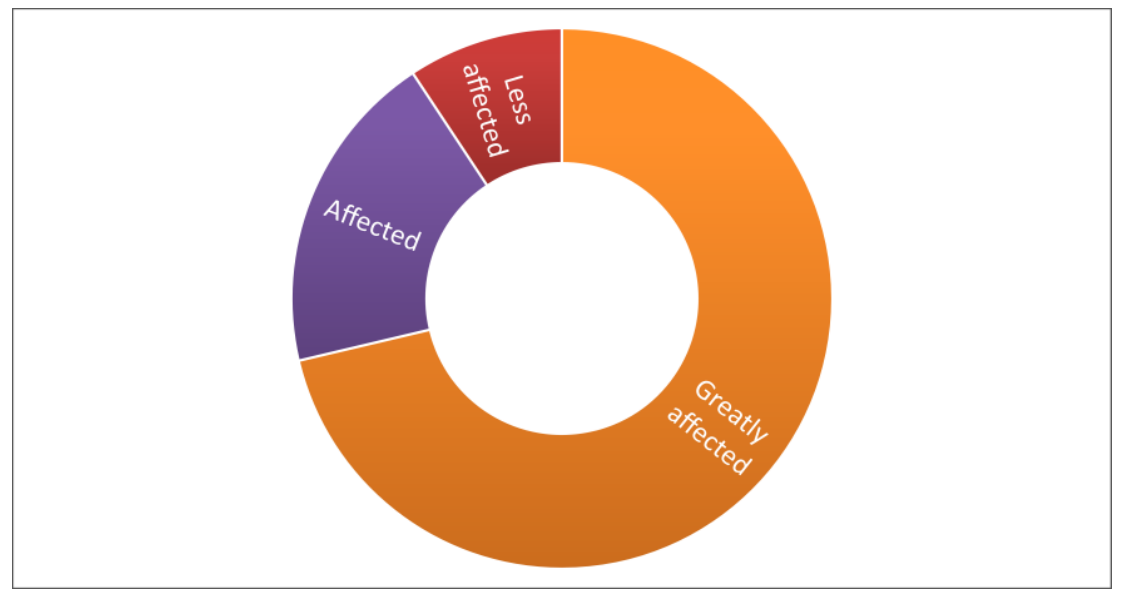

Figure 1:- Percentage of stores affected to varying degrees

The survey results showed that the COVID-19 pandedemic greatly affected catering business in Tan Thinh ward. 100\% of stores were affected to varying degrees. In which, $71.3 \%$ of stores were greatly affected (corresponding: group 1 was $73.6 \%$; group 2 was $64.24 \%$; and group 6 was $76.33 \%$ ).

Stores near universities were most severely affected (in group 1, group 2) because these were where business activities depend heavily on the number of students. The pandemic lasted for a long time, students studied online at home, so the number of customers to the stores decreased. Some stores located in small alleys had to reduce business time to 1 session instead of 2 sessions a day as before. In addition, customers were afraid of the pandemic, so they tend to take away without eating at the store. $100 \%$ of the stores said that the number of customers eating at the stores was greatly reduced. In particular, according to regulations in Vietnam, at some times when infected people appear in the community, restaurants were only allowed to sell takeaway to control the pandemic. As a result, the number of single-use plastic bags and items also increased. The article also showed types of stores affected by the COVID-19 pandemic (table 3 , figure 2).

Table 3:- Types of catering store affeced by COVID-19

\begin{tabular}{ccccccc}
\hline \multirow{2}{*}{ Groups } & \multirow{2}{*}{ Influence level } & \multicolumn{5}{c}{ Percentage of types of stores affected (\%) } \\
\cline { 3 - 7 } & $(0)$ & 0 & Type II & Type III & Type IV & Type $V$ \\
\hline \multirow{4}{*}{ Group 1 } & $(1)$ & 25 & 9.5 & 0 & 0 & 0 \\
& $(2)$ & 50 & 14.3 & 0 & 0 & 16.6 \\
& $(3)$ & 25 & 76.2 & 100 & 81.2 & 66.8 \\
\hline \multirow{5}{*}{ Group 2 } & $(0)$ & 0 & 0 & 0 & 0 & 0 \\
& $(1)$ & 66.6 & 10 & 0 & 0 & 20 \\
& $(2)$ & 33.4 & 20 & 0 & 27.3 & 40 \\
Group 6 & $(3)$ & 0 & 70 & 100 & 73.7 & 40 \\
& $(0)$ & 0 & 0 & 0 & 0 & 0 \\
& $(1)$ & 100 & 13.3 & 0 & 0 & 0 \\
\multirow{5}{*}{ Total } & $(2)$ & 0 & 13.3 & 12.5 & 20 & 25 \\
& $(3)$ & 0 & 73.4 & 87.5 & 80 & 75 \\
\hline & $(0)$ & 0 & 0 & 0 & 0 & 0 \\
& $(1)$ & 50 & 10.7 & 0 & 0 & 13.3 \\
& $(2)$ & 37.5 & 16.1 & 7.7 & 21.6 & 26.7 \\
\hline
\end{tabular}

*Source: Surveyed results in September 2021

Ghi chú:

Type I: Street stand stores

Type II: Small restaurants

Type III: Great restaurants
(0): Unaffected

(1): Less affected

(2): Affected 
Type IV: Drink, fastfood stores

Type V: Sidewalk refreshments
(3): Greatly affected

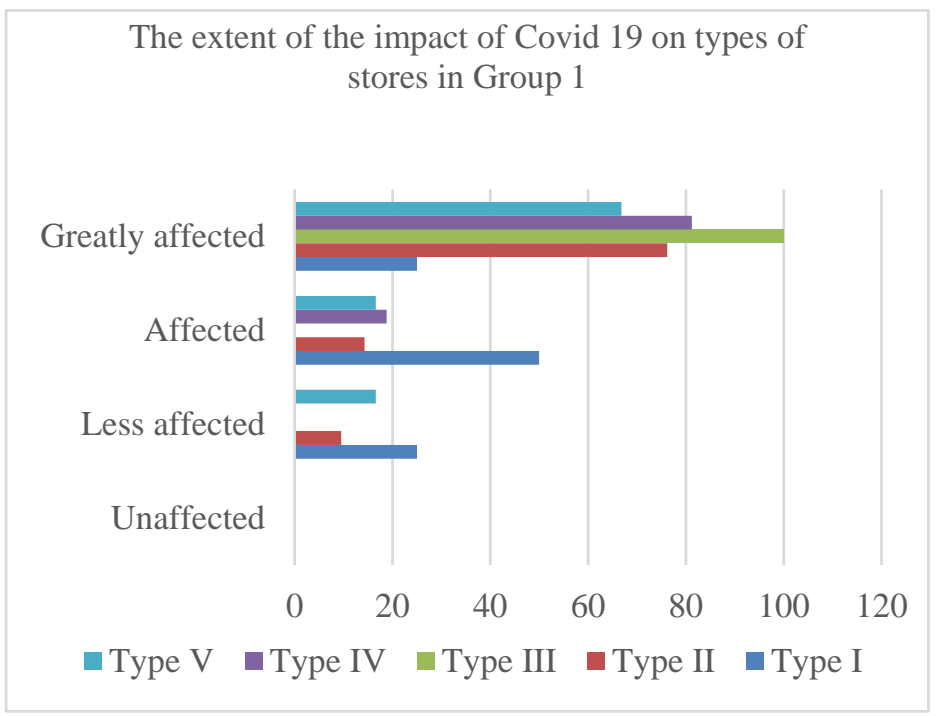

(a)

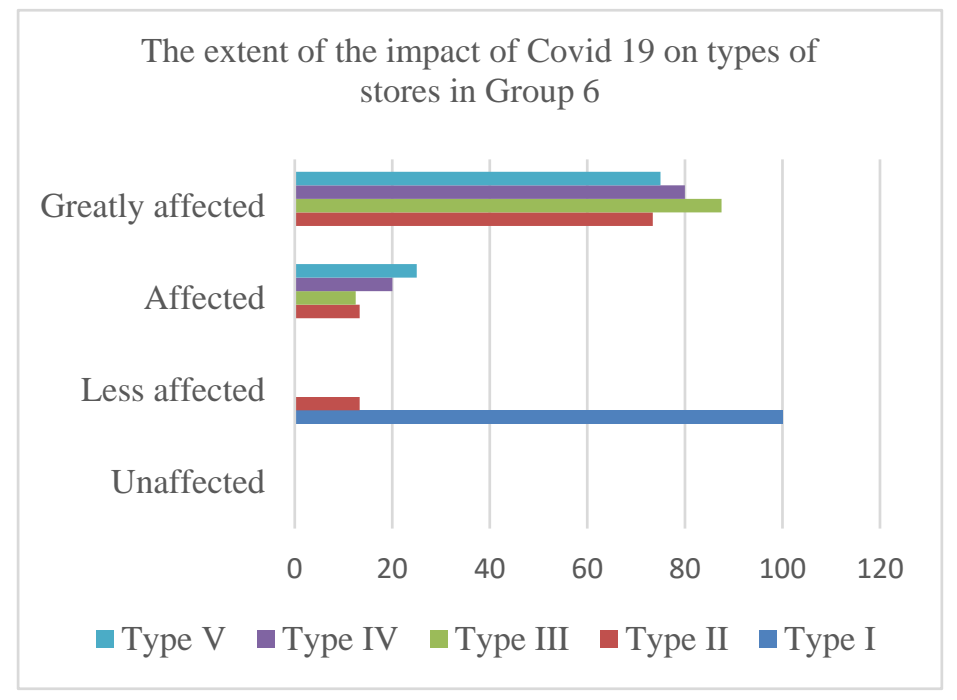

(c)

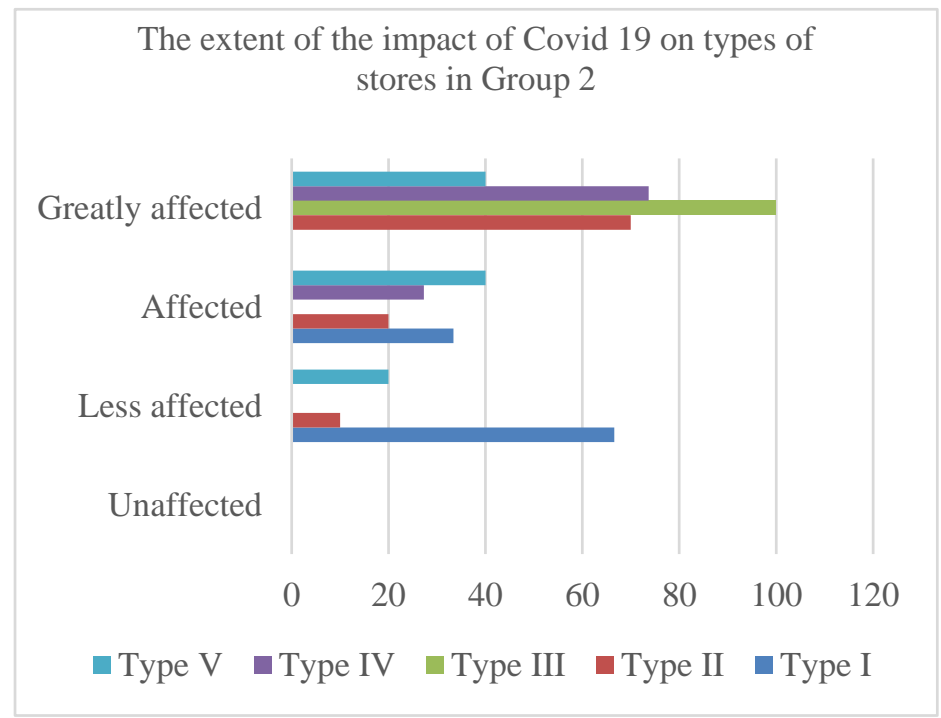

(b)

The extent of the impact of Covid 19 on types of stores of 3 groups

Greatly affected

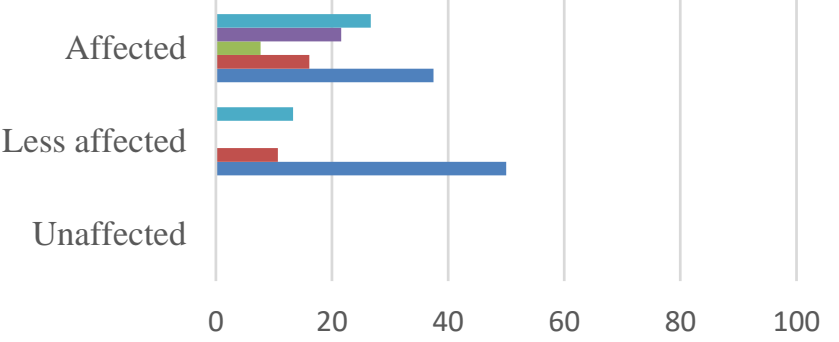

Type V $\square$ Type IV $\square$ Type III $\square$ Type II $\square$ Type I

Figure 2:- Graph of the impact of the COVID-19 pandemic on types of catering stores in Tan Thinh ward
(a) Group 1
(b) Group 2
(c) Group 6
(d) 3 groups

Great restaurants (type III) were most affected by the COVID 19 pandemic. $92.3 \%$ of surveyed stores said that the pandemic had a great impact on store business. Because customers often eat at the restaurant when choosing great restaurants. Therefore, when restaurants were only allowed to sell takeaways, most of these restaurants closed. Some stores said that they switched to online business, delivered food to customers' homes, but the quantity was not much.

The type of store least affected was street stand stores. Only $12.5 \%$ of stores in this type said that they were greatly affected by the pandemic. Because the specialty of this type of store was to serve takeaway food. So when the pandemic appeared, except in times of extreme stress, the number of customers coming to the store was not affected much. 
In general, the COVID-19 pandemic greatly affected the catering business in Tan Thinh ward.

\subsection{Impact of the Covid 19 pandemic on the generation of plastic waste of catering stores in Tan Thinh ward}

The use of single-use plastics and plastic bags to store takeaway food was quite common at the restaurants of Tan Thinh ward. Survey results showed that $100 \%$ of stores in Tan Thinh ward used plastic bags and single-use plastic in food storage to varying degrees. $100 \%$ of street stand stores (type I) and drink - fastfood stores (type IV) used plastic bags and single use plastics on a regular basis. $100 \%$ of great stores surveyed said that they did not use too many plastic bags and single-use plastics to store food because these restaurants mainly serve customers eating at the restaurant. These plastic containers were only used when guests brought home leftovers. The results also showed that with different types of food, the amount of plastic bags and single-use plastics used was also different. Easy-to-go foods use more plastic bags and single-use plastics. Specifically, stores selling sticky rice, bread, steamed wheat flour cake... used more plastic bags and single-use plastics than stores selling noodle soup, stuffed pancake...

The results of a survey of 129 catering stores in Tan Thinh ward on the use of plastic before and after the COVID-19 appearance were shown in the table 4.

Table 4:- Level of use of plastic bags and single-use plastics before and after the COVID-19 appearance

\begin{tabular}{|c|c|c|c|c|c|}
\hline \multirow[t]{2}{*}{ Group } & \multirow[t]{2}{*}{ Types of store } & \multirow{2}{*}{$\begin{array}{l}\text { Number } \\
\text { of stores }\end{array}$} & \multicolumn{3}{|c|}{$\begin{array}{c}\text { The level of using plastic bags and single-use plastics before and after the } \\
\text { appearance of the COVID-19 pandemic (\%) }\end{array}$} \\
\hline & & & No change & Less & More \\
\hline \multirow[t]{5}{*}{ Group 1} & Type I & 4 & 50 & 50 & 0 \\
\hline & Type II & 21 & 28.6 & 28.6 & 42.8 \\
\hline & Type III & 2 & 50 & 50 & 0 \\
\hline & Type IV & 16 & 31.3 & 50 & 18.7 \\
\hline & Type V & 6 & 50 & 33.3 & 16.7 \\
\hline \multirow[t]{5}{*}{ Group 2} & Type I & 3 & 33.3 & 66.7 & 0 \\
\hline & Type II & 20 & 40 & 25 & 35 \\
\hline & Type III & 3 & 33.3 & 66.7 & 0 \\
\hline & Type IV & 11 & 27.3 & 54.5 & 18.2 \\
\hline & Type V & 5 & 60 & 0 & 40 \\
\hline \multirow[t]{5}{*}{ Group 6} & Type I & 1 & 100 & 0 & 0 \\
\hline & Type II & 15 & 33.3 & 26.7 & 40 \\
\hline & Type III & 8 & 25 & 75 & 0 \\
\hline & Type IV & 10 & 30 & 50 & 20 \\
\hline & Type V & 4 & 50 & 50 & 0 \\
\hline \multirow[t]{5}{*}{ Total } & Type I & 8 & 50 & 37.5 & 12.5 \\
\hline & Type II & 56 & 33.9 & 26.8 & 39.3 \\
\hline & Type III & 13 & 30.8 & 69.2 & 0 \\
\hline & Type IV & 37 & 29.7 & 51.4 & 18.9 \\
\hline & Type V & 15 & 53.3 & 20 & 26.7 \\
\hline
\end{tabular}

*Source: Surveyed results in September 2021

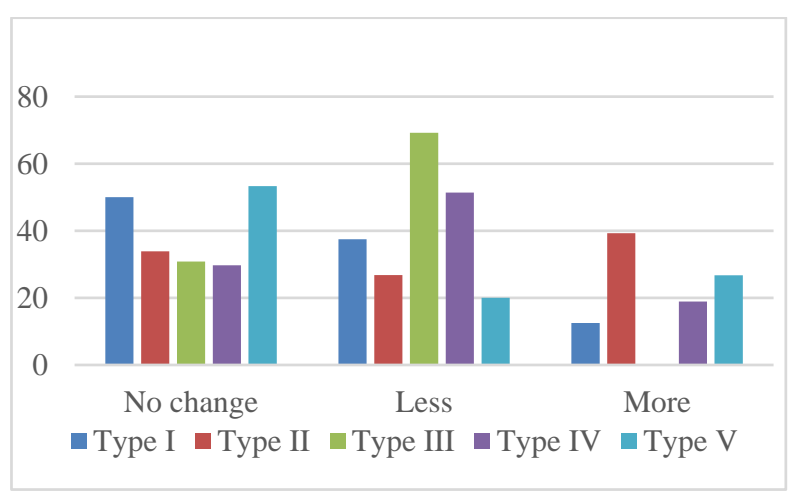

Figure 3:- Graph of the level of using plastic bags and single-use plastics before and after the COVID-19 appearance

Although the situation of the COVID-19 pandemic was quite complicated and affected the catering business in Tan Thinh ward, it did not much impact on the amount of plastic bags and single-use plastics generated in some stores. Specifically, 50\% of the stores of type I; $33.9 \%$ of stores of type II; $30.8 \%$ stores of type III; $29.7 \%$ of stores of type IV and $53.3 \%$ of stores of type V said that the amount 
of plastic bags and single-use plastics used in the store's business did not change. Although the number of customers was lower than before the pandemic, the number of take-out customers was almost unchanged. At some stores, the number of take-out customers increased more than before the pandemic. 39.3\% of type II stores (selling stuffed pancake, kebab rice noodles, noodle soup, fried rice...) said that the use of plastic bags and single-use plastics increased more than before the pandemic. Because these stores had a fairly stable number of customers. Customers did not eat at the restaurant but they still went to the store to buy and take away.

Stores in type III were most affected by the COVID-19 pandemic, so $100 \%$ of stores in this type said that they used less plastic bags and single use plastic than before the pandemic. The COVID-19 pandemic had a great impact on customer psychology. The tendency of customers to take away food was also the reason for the increase in the amount of plastic bags and single-use plastics.

The storage of foods and drinks with plastic bags and single use plastics (styrofoam boxes, plastic cups, plastic spoons...) caused adverse effects on human health if used regularly. Besides, after disposing of them, they caused a great impact on the environment. Therefore, it is necessary to have suitable solutions to manage plastic waste in a reasonable way.

\subsection{Discussion}

The article showed that the COVID-19 pandemic had a great impact on catering business in Tan Thinh ward. In which, great restaurants were most seriously affected by the pandemic. Many stores had to close during outbreaks. However, the amount of plastic bags and single-use plastics depended on the item and the type of business of stores. Small stores, selling items such as sticky rice, bread, kebab rice noodles, Stuffed pancake ... used plastic bags and single-use plastics more. And great stores have reduced plastic bags and single-use plastics because customers did not choose to buy items from the store for takeout. Thus, the COVID-19 pandemic had increased the amount of plastic used in some types of catering businesses. This announcement was consistent with some previous announcements by Ana L.Patrício Silvaa [3], Nsikak U.Benson [11], which suggested that COVID-19 increased the amount of plastic waste released into the environment.

With the given results, the article shows the impact of the COVID-19 pandemic on the generation of plastic waste in an area in Vietnam. Thereby, as a basis for management and propose appropriate solutions.

\section{CONCLUSION}

The results showed that the catering business was greatly affected by the COVID-19 pandemic. The amount of plastic used depends a lot on the size and type of business. Great restaurants used less plastic containers than small stores. Stores that sold takeaways also use more plastic bag and single-use plastics .

\section{ACKNOWLEDGEMENTS}

To complete this research I would like to thank the financial support of Thai Nguyen University of science. I would also like to thank the People's Committee of Tan Thinh Ward, Thai Nguyen city for providing me with documents and assisting me during the survey in the area.

\section{REFERENCES}

1. Vietnam's Ministry of Health Portal on the COVID 19 pandemic, [online] https://covid19.gov.vn/

2. Ministry of Investment Planning, General Statistics Office, Report on the impact of the Covid-19 epidemic on the labor and employment situation in the third quarter of 2021, October 12, 2021, Hanoi, Vietnam.

3. Ana L.Patrício Silva, Joana C.Prata, Tony R.Walker, Armando C.Duarte, WeiOuyang, DamiàBarcelò, TeresaRocha-Santos, Increased plastic pollution due to COVID-19 pandemic: Challenges and recommendations, Chemical Engineering Journal, Volume 405, 1 February 2021, 126683

4. NormanEbner, Elenilacovidou, The challenges of Covid-19 pandemic on improving plastic waste recycling rates, Sustainable Production and Consumption

1. Volume 28, October 2021, Pages 726-735

5. Thijs Geijer, Plastic packaging in the food sector Six ways to tackle the plastic puzzle, ING Economics Department, 12/2019.

6. J. R. Jambeck et al., "Plastic waste inputs from land into the ocean", Science, no. 347, pp. 768-771, 2015.

7. W. M. Morgana et al., "Plastic Food Packaging: Perceptions and Attitudes of Portuguese Consumers about Environmental Impact and Recycling", Sustainability 2021, vol.13, no. 17, 2021

8. T. H. Tran, Research and survey the current status of plastic waste in Vietnam, (in Vietnammese), Plastic SmartCities Proposal, WWF, 2015.

9. T. A. Duong et al. (IUCN), Microplastic pollution: a case study in Vietnam and international experience, (in Vietnammese), Transport Publishing House company limitesd, 2021.

10. People's Committee of Tan Thinh Ward, Report on implementation of socio-economic development tasks in 2020 and directions and tasks of socio-economic development in 2021, Thai Nguyen, 2020.

11. Nsikak U.Benson, David E.Bassey,ThavamaniPalanisami, COVID pollution: impact of COVID-19 pandemic on global plastic waste footprint, Heliyon 7(2021) e06343 


\section{AUTHORS}

First Author - Thi Ngoc Ha Tran, Thai Nguyen University of Science, Vietnam

Correspondence Author - Thi Ngoc Ha Tran, Thai Nguyen University of Science, Vietnam hattn@tnus.edu.vn 